\title{
INFLUENCE OF PLASMA NITRIDING ON CHANGE OF PART SIZE AND CHANGE OF FUNCTIONAL PARAMETERS OF SURFACE ROUGHNESS OF 34CrNiMo6 AND 14NiCr14 STEELS
}

\author{
${ }^{1}$ David DOBROCKÝ, 'Zbyněk STUDENÝ, ' Jiří PROCHÁZKA, ${ }^{1}$ Emil SVOBODA \\ ${ }^{1}$ University of Defense, Faculty of Military Technology, Brno, Czech Republic, EU, \\ david.dobrocky@unob.cz,zbynek.studeny@unob.cz, iiri.prochazka@unob.cz, emil.svoboda@unob.cz
}

https://doi.org/10.37904/metal.2021.4191

\begin{abstract}
Due to the increasing requirements for ensuring the function of the component and technical units in operation, monitoring and influencing chemical and physical changes in the properties of materials in the surface layer of the component is of considerable importance. These changes take place both as a result of the machining process, but can also be significantly influenced by the formation of diffusion layers, using suitable surface technology. These technologies include, for example, plasma nitriding, which significantly increases the useful properties of the surface. However, plasma nitriding also has a direct effect on the geometric quality of the surface of the part, ie the process of saturating the surface with interstitial elements initiates structural stress mechanisms, which lead to changes in surface structure and dimensional changes. The presented article deals with the evaluation of the change in dimensions and the change in the surface roughness of samples from medium-alloyed, noble steels $34 \mathrm{CrNiMo} 6$ and $14 \mathrm{NiCr} 14$. The change in the longitudinal dimension of the samples was evaluated using a 3D coordinate measuring machine and the surface roughness using a coherent correlation interferometer (non-contact). The evaluation of the surface roughness was focused on the change of $2 \mathrm{D}$ functional parameters Rk, Rpk, Rvk and the height parameters $R a$ and $R z$ were also evaluated. The dimensional changes were higher for $14 \mathrm{NiCr} 14$ steel $(0.030 \mathrm{~mm})$, compared to $34 \mathrm{CrNiMo} 6$ steel $(0.023 \mathrm{~mm})$. The nitriding process further led to changes in the evaluated 2D parameters of the surface roughness, which were more pronounced for $14 \mathrm{NiCr} 14$ steel.
\end{abstract}

Keywords: Plasma nitriding, surface roughness, change of size, functional parameter

\section{INTRODUCTION}

A significant shift in the development of technologies and materials was the introduction of methods of chemical-heat treatment of exposed components, especially carburizing, nitriding and their modifications. These technologies are currently also penetrating the field of additive technologies [1]. The machined surfaces are saturated with interstitial elements and diffusion into the base material significantly increases the hardness of the surface layer. The formed surface layer acquires increased resistance to corrosion and fatigue failure, there is an increase in wear resistance and the initiation of compressive residual stresses in the surface layer $[2,3,4,5]$.

The issue of the influence of chemical-heat treatment on dimensional accuracy and change of surface texture is addressed very little. Dimensional changes after nitriding processes are discussed, for example, in [6]. For instance, the publications $[7,8]$ describe in more detail the deformation and transformation mechanisms in chemical-heat treatment, which lead to an increase in the volume of components and thus to changes in dimensional accuracy.

The main reason for the change in dimensional accuracy and surface texture in nitriding is mainly the phase conversion of austenite to martensite, which causes an increase in their volume. Another factor is the diffusion 
of nitrogen into the steel surface, which leads to an increase in the volume of the white layer (up to $5 \%$ ). In the work [9] it is stated that the change of the dimension of the part is proportional to the thickness of the white layer. When examining the effect of nitriding on the dimensional accuracy of $\mathrm{C} 45$ and $16 \mathrm{MnCr} 5$ steel components, it was found that the dimensional increase is $30 \%$ to $50 \%$ of the thickness of the white layer [10].

Dimensional accuracy can also be significantly affected by the shape deformation of the part, which is caused by the distribution of internal stresses in the material. Stress in the material arises both in the production of semi-finished products by forming and in phase transformations during heat treatment, chemical-heat treatment and subsequent cooling of the component. As a result of the deformation of the matrix lattice, which is caused by supersaturation of the ferrite with nitrogen, microscopic stresses of the diffusion layer occur. Nitrogen supersaturation of ferrite can reach up to $300 \%$ of the equilibrium nitrogen concentration [11]. In the case of nitriding, precipitation of nitrides induces long-range tension fields, especially in the vicinity of coherent precipitates. If the precipitation processes take place until the formation of stable $\mathrm{Y}^{\prime}-\mathrm{Fe}_{4} \mathrm{~N}$ type precipitates, the result is a significant reduction in stress, however, their formation is accompanied by an increase in volume and the emergence of macroscopic compressive stresses [12]. These mechanisms therefore lead to changes in the dimensions and surface texture of the components.

\section{EXPERIMENTAL PROCEDURE}

\subsection{PRODUCTION OF SAMPLES AND THEIR PROCESSING}

Experimental samples with dimensions of $30.6 \mathrm{~mm} \times 20.6 \mathrm{~mm}$ and length of $90.6 \mathrm{~mm}$ were made from selected steels. Samples were made with a $0.3 \mathrm{~mm}$ machining allowance. A total of 5 samples of each steel were produced. The chemical composition of the steels was evaluated using a Q4 Tasman spark optical spectrometer and the results are documented in (Table 1).

Table 1 Chemical composition of evaluated steels (wt\%)

\begin{tabular}{|c|c|c|c|c|c|c|c|}
\hline $\mathbf{C}$ & $\mathbf{M n}$ & $\mathbf{S i}$ & $\mathbf{C r}$ & $\mathbf{N i}$ & $\mathbf{C u}$ & $\mathbf{P}$ & $\mathbf{S}$ \\
\hline \multicolumn{7}{|c|}{ 34CrNiMo6 } \\
\hline 0.36 & 0.76 & 0.25 & 1.65 & 1.94 & 0.20 & 0.019 & 0.034 \\
\hline \multicolumn{7}{|c|}{$\mathbf{1 4 N i C r 1 4}$} \\
\hline 0.10 & 0.60 & 0.25 & 0.80 & 3.33 & 0.17 & 0.010 & 0.020 \\
\hline
\end{tabular}

The experimental samples were heat treated, i.e. normalized and treated according to the recommendations given in the material sheets. The heat treatment parameters are given in (Table 2).

Table 2 Parameters of heat treatment of experimental samples

\begin{tabular}{|l|l|l|l|}
\hline \multicolumn{1}{|c|}{ Steel } & \multicolumn{1}{c|}{ Normalization annealing } & \multicolumn{1}{c|}{ Hardening } & \multicolumn{1}{c|}{ Tempering } \\
\hline $34 \mathrm{CrNiMo} 6$ & $870^{\circ} \mathrm{C} / 45 \mathrm{~min} /$ air & $850^{\circ} \mathrm{C} / 45 \mathrm{~min} /$ oil & $600{ }^{\circ} \mathrm{C} / 100 \mathrm{~min} /$ water \\
\hline $14 \mathrm{NiCr} 14$ & $850^{\circ} \mathrm{C} / 45 \mathrm{~min} /$ air & $840{ }^{\circ} \mathrm{C} / 45 \mathrm{~min} /$ water & $600{ }^{\circ} \mathrm{C} / 100 \mathrm{~min} /$ water \\
\hline
\end{tabular}

The heat treatment of the experimental samples was followed by grinding of the functional surfaces. The final dimensions of the sample were determined to be $-\mathrm{L} \times \mathrm{W} \times \mathrm{H}=90 \mathrm{~mm} \times 30 \mathrm{~mm} \times 20 \mathrm{~mm}$. The surface roughness requirements for ground surfaces were set to $\mathrm{Ra}=0.8 \mu \mathrm{m}$. The samples thus prepared were plasma nitrided at $520^{\circ} \mathrm{C}$ for $14 \mathrm{~h}$ in an atmosphere of $1 \mathrm{H}_{2}: 3 \mathrm{~N}_{2}$ in Rübig PN 100/180 device.

\subsection{Measurement of parameters of diffusion layers, changes in size and surface roughness}

The change in the parameters of the diffusion layer after plasma nitriding was evaluated in terms of surface hardness, measuring the depth of the diffusion layer and the thickness of the white layer. The surface hardness 
was measured on an instrumented Zwick ZHU 2.5 hardness tester, with a load of $10 \mathrm{~kg}$ (HV10). The depths of the diffusion layers were measured using microhardness and hardness curves on an automated Leco LM247AT microhardness tester, with a load of $100 \mathrm{~g}$ (HV0.1). The thicknesses of the white layers were measured optically on a metallographic cross-section of sample, using an Olympus DSX500 inverted optodigital metallographic microscope, at 1000x magnification.

Measurement of dimensional accuracy of experimental samples was performed on a 3D CNC coordinate machine Werth ScopeCheck $\circledast S$ and evaluated by WinWerth $\circledast 8$ software. Dimensional changes were evaluated by a touch sensor.

The surface roughness parameters were measured by the non-contact method with a Talysurf CCI Lite coherent correlation interferometer. The obtained data were analyzed using MountainsLab Premium 8 software. The measurement was performed on the sampling length $\mathrm{Ir}=0.8 \mathrm{~mm}$, evaluated length $\mathrm{In}=4 \mathrm{~mm}$, cut-off $\Delta \mathrm{c}=0.8 \mathrm{~mm}$, Gauss filtration. A total of 5 roughness profiles were measured and the mean value was taken from them.

\section{EXPERIMENTAL RESULTS AND DISCUSSION}

\subsection{Results of measuring parameters of diffusion layers}

The evaluated parameters of the diffusion layers are shown in (Figure 1) in the case of surface hardness and in (Figure 2) in the evaluation of the depth of the diffusion layer and the thickness of the white layer.

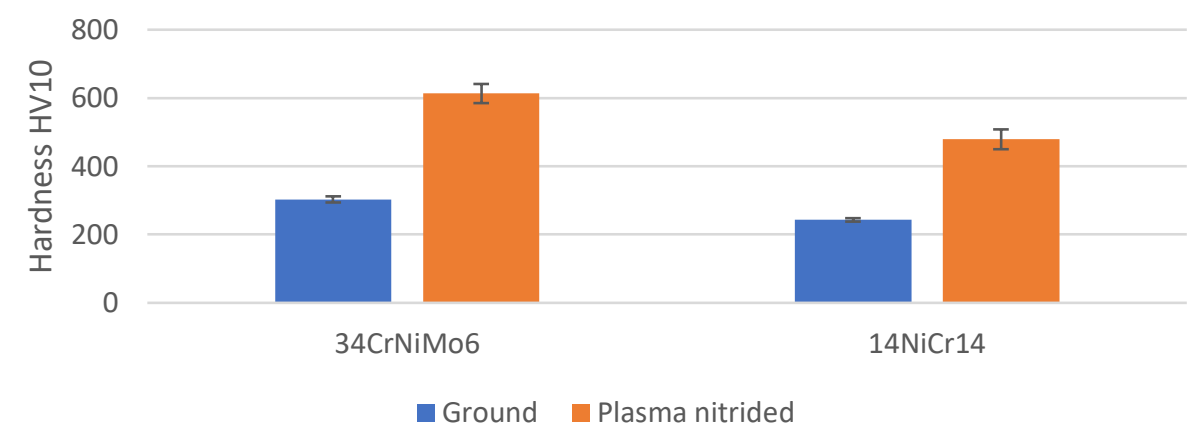

Figure 1 Surface hardness before and after plasma nitriding

A more significant increase in surface hardness can be observed for $34 \mathrm{CrNiMo6}$ steel (613 $\pm 28 \mathrm{HV} 10)$, compared to $14 \mathrm{NiCr} 14$ steel $(479 \pm 29 \mathrm{HV} 10)$.

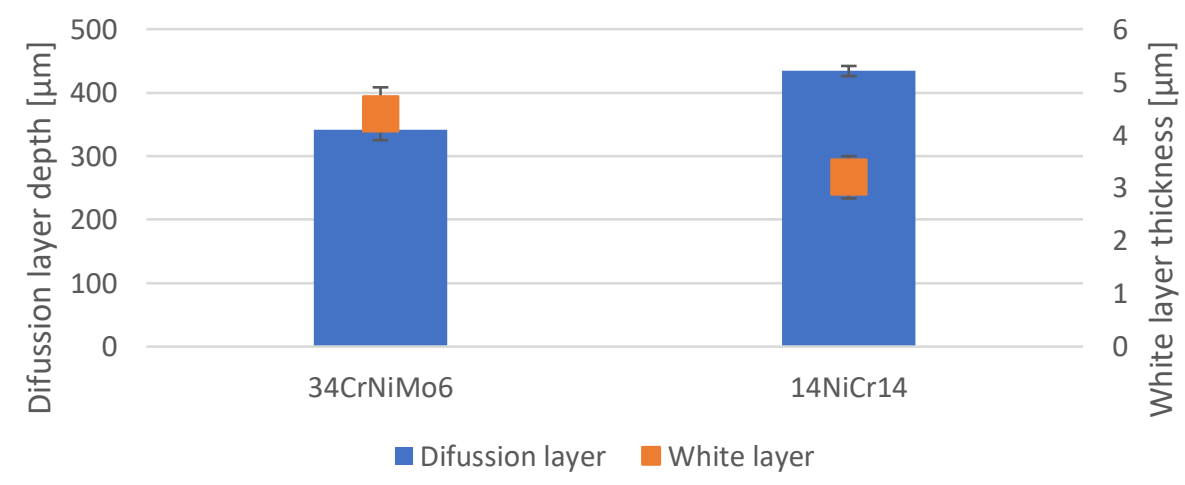

Figure 2 Diffusion layer depth and white layer thickness 
Conversely, in the case of diffusion layer depths, a higher value was detected for $14 \mathrm{NiCr} 14$ steel $(434 \pm 8 \mu \mathrm{m})$, compared to $34 \mathrm{CrNiMo} 6$ steel $(342 \pm 1 \mu \mathrm{m})$. The thicknesses of the white layers were reversed, a higher value $(4.4 \pm 0.5 \mu \mathrm{m})$ was found for $34 \mathrm{CrNiMo} 6$ steel, compared to the value $(3.2 \pm 0.4 \mu \mathrm{m})$ for $14 \mathrm{NiCr} 14$ steel.

\subsection{Results of dimensional change measurement}

The values of changes in the dimensions of the experimental samples, given in Table 3, express the mean value from 5 measurements. These values of changes are compared with the mean value of the treated ground samples, which here represents the reference value 0 , resp. required sample size $90 \mathrm{~mm}$.

Table 3.1 Change in dimensions of experimental samples after plasma nitriding

\begin{tabular}{|c|c|c|}
\hline Steel & Change of dimension $[\mathrm{mm}]$ & Change the degree of IT accuracy \\
\hline 34CrNiMo6 & $+0.023 \pm 0.002$ & from IT 6 to IT7 \\
\hline 14NiCr14 & $+0.030 \pm 0.003$ & from IT7 to IT8 \\
\hline
\end{tabular}

The results given in (Table 3) show an increase in dimensions after the plasma nitriding process, which reached almost identical values for both steels. The same values were achieved by the deterioration of the degree of accuracy of ground samples by the application of the plasma nitriding process, by one degree of IT accuracy.

\subsection{Results surface roughness evaluation}

To evaluate the change in roughness of machined surfaces after plasma nitriding, 2 groups of $2 \mathrm{D}$ roughness profile parameters were selected, which objectively describe changes in surface microgeometry and basic characteristics of the functional behavior of the component in operation. The selection of parameters was performed with the aim of a basic description of the change in the roughness of the machined surface, in terms of the change in the geometric accuracy of the part after the plasma nitriding process. The selection of parameters is given in (Table 4).

Table 4 Selected 2D surface roughness parameters

\begin{tabular}{|l|l|l|}
\hline \multicolumn{1}{|c|}{ Parameter designation } & \multicolumn{1}{c|}{ Full name } & Unit \\
\hline \multicolumn{3}{|c|}{ Amplitude (height) parameters } \\
\hline $\mathrm{Ra}$ & Arithmetic Mean Deviation of the roughness profile & $\mu \mathrm{m}$ \\
\hline $\mathrm{Rz}$ & Maximum Height of roughness profile & $\mu \mathrm{m}$ \\
\hline \multicolumn{1}{|l|}{$\boldsymbol{R k}$ parameters (parameters of material ratio) } & $\mu \mathrm{m}$ \\
\hline $\mathrm{Rk}$ & Core Roughness & $\mu \mathrm{m}$ \\
\hline $\mathrm{Rpk}$ & Reduced Peak Height & $\mu \mathrm{m}$ \\
\hline $\mathrm{Rvk}$ & Reduced Valley Depth & \\
\hline
\end{tabular}

The results of the evaluation of selected 2D parameters of the roughness profile are documented for steel $34 \mathrm{CrNiMo} 6$ in (Table 5). Table 6 shows the results of the evaluation of $14 \mathrm{NiCr} 14$ steel.

From the results given in (Table 5) it is evident that the changes of the evaluated roughness parameters did not reach significant values for $34 \mathrm{CrNiMo} 6$ steel, resp. the process of plasma nitriding did not lead to changes in height and functional parameters of surface roughness. The only exception is the Rvk parameter, where a decrease of $17 \%$ was achieved after the plasma nitriding process. Decreasing the value of this parameter is characterized by poorer retention of the lubricant by the surface. 
Significant differences were achieved in the evaluation of $14 \mathrm{NiCr} 14$ steel, there was an increase in the parameter Ra by $15 \%$ after the plasma nitriding process, which indicates a deterioration in surface roughness. In the case of the $\mathrm{Rz}$ parameter, its increase by $26 \%$ was measured, compared to the ground surface. This indicates a higher probability of this profile penetrating the oil film. In the case of the parameter Rk, it decreased after plasma nitriding by $19 \%$, the nitrided surface will wear more slowly. An increase in the Rpk parameter by $48 \%$ after plasma nitriding means more friction particles at the sliding surfaces, which are formed by breaking the tips of the profile peaks. On the contrary, an increase in the value of the Rvk parameter by $84 \%$ after plasma nitriding will cause the surface to better retain the lubricant in its valleys.

Table 5 Change of surface texture parameters for $34 \mathrm{CrNiMo6}$ steel

\begin{tabular}{|l|c|c|c|c|}
\hline \multirow{2}{*}{ Parameter } & \multicolumn{2}{|c|}{ Process } & \multicolumn{2}{c|}{ Change of values } \\
\cline { 2 - 5 } & Ground & Plasma nitrided & {$[\mu \mathrm{m}]$} & {$[\%]$} \\
\hline $\mathrm{Ra}$ & $0.98 \pm 0.14$ & $0.95 \pm 0.02$ & -0.03 & -3 \\
\hline $\mathrm{Rz}$ & $6.33 \pm 0.97$ & $6.13 \pm 0.10$ & -0.20 & -3 \\
\hline $\mathrm{Rk}$ & $2.86 \pm 0.41$ & $2.84 \pm 0.13$ & -0.02 & -1 \\
\hline $\mathrm{Rpk}$ & $0.93 \pm 0.16$ & $0.96 \pm 0.10$ & +0.03 & +3 \\
\hline $\mathrm{Rvk}$ & $2.17 \pm 0.15$ & $1.81 \pm 0.14$ & -0.36 & -17 \\
\hline
\end{tabular}

Table 6 Change of surface texture parameters for $14 \mathrm{NiCr} 14$ steel

\begin{tabular}{|l|c|c|c|c|}
\hline \multirow{2}{*}{ Parameter } & \multicolumn{2}{|c|}{ Process } & \multicolumn{2}{c|}{ Change of values } \\
\cline { 2 - 5 } & Ground & Plasma nitrided & {$[\mu \mathrm{m}]$} & {$[\%]$} \\
\hline $\mathrm{Ra}$ & $0.71 \pm 0.10$ & $0.82 \pm 0.05$ & +0.11 & +15 \\
\hline $\mathrm{Rz}$ & $4.23 \pm 0.22$ & $5.31 \pm 0.16$ & +1.08 & +26 \\
\hline $\mathrm{Rk}$ & $2.31 \pm 0.45$ & $1.88 \pm 0.18$ & -0.43 & -19 \\
\hline $\mathrm{Rpk}$ & $0.52 \pm 0.09$ & $0.77 \pm 0.05$ & +0.25 & +48 \\
\hline $\mathrm{Rvk}$ & $1.22 \pm 0.19$ & $2.24 \pm 0.13$ & +1.02 & +84 \\
\hline
\end{tabular}

\section{CONCLUSION}

The plasma nitriding process led to similar values of the increase in the dimensions of the experimental samples in the evaluated steels (on average by $26.5 \mu \mathrm{m}$ ). Of the evaluated steels, a smaller average value of the dimensional increase was found for $34 \mathrm{CrNiMo} 6$ steel. For both steels, the process led to a deterioration of one degree of IT accuracy.

Experimental research further showed that the process of plasma nitriding leads to changes in the observed 2D parameters of the roughness profile. Negligible changes in roughness were found for $34 \mathrm{CrNiMo6}$ steel. However, in $14 \mathrm{NiCr} 14$ steel, the plasma nitriding process led to significant changes in all evaluated parameters. The results show that $34 \mathrm{CrNiMo} 6$ steel is suitable for the plasma nitriding process in terms of changing the functional properties of the surface, to which it is not sensitive. In contrast, in $14 \mathrm{NiCr} 14$ steel, the plasma nitriding process leads to changes in functional properties, which are manifested by deterioration of roughness, worse friction parameters, but higher wear resistance and better ability to retain lubricant.

The achieved results correspond to the results achieved in the work $[6,13]$ and expand the area of solving the problem of the influence of chemical-thermal treatment on the quality of components. Despite its undeniable advantages that plasma nitriding has, it is necessary to realize that this process affects the geometric parameters of components. For this reason, it is necessary to include a thorough control of the dimensions and texture of the surface after the nitriding processes, especially for components whose functional surfaces are manufactured to the prescribed degree of accuracy. Another possibility is to use such steels which are not very sensitive to the above-mentioned changes in geometric parameters. 


\section{ACKNOWLEDGEMENTS}

The paper has been prepared thanks to the support of the project "VAROPS (DZRO FVT 3) Military autonomous and robotic systems" and Surface technology in applications special techniques SV20216.

\section{REFERENCES}

[1] ROBL, J., SEDLAK, J., POKORNY, Z., NUKSA, P., BARENYI, I., MAJERIK, J. Analysis of advanced additive technology in direct metal laser sintering and precision casting method. Bulletin of the Polish Academy of Sciences, Technical Sciences. 2020, vol. 68, no. 1, pp. 109-118.

[2] JOSKA, Z., POKORNÝ, Z., KADLEC, J., STUDENÝ, Z., SVOBODA, E. Hardness of nitrided layers treated by plasma nitriding. Acta Polytechnica CTU Proceedings. Praha: Czech Technical University, 2020, vol. 27, pp. 5356.

[3] KUSMIČ, D., DOAN, T.V. Tribological and corrosion properties of plasma nitrided and nitrocarburized 42CrMo4 steel. IOP Conference Series: Materials Science and Engineering. 2017.

[4] RAO, K.R.M., TRINADH, K., NOUVEA, C. Glow discharge plasma nitriding of low alloy steel. Materialstoday: PROCEEDINGS. 2019, vol. 19, no. 2, pp. 864-866.

[5] BUMBALEK, M., JOSKA, Z., POKORNY, Z., SEDLAK, J., MAJERIK, J., NEUMANN, V., KLIMA, K. Cyclic Fatigue of Dental NiTi Instruments after Plasma Nitriding. Materials. 2021, vol. 14, no. 9, p. 2155.

[6] DOBROCKÝ, David, POKORNÝ, Zdeněk, STUDENÝ, Zbyněk, JOSKA, Zdeněk, PROCHÁZKA, Jiří, SVOBODA, Emil. The influence of nitriding on the geometric accuracy of parts of special technology. In: 29th International Conference on Metallurgy and Materials - METAL 2020. Ostrava, Czech Republic: Tanger Ltd., 2020, pp. 618626.

[7] JACOBS, H., RECHENBACH, D., ZACHWIEJA, U. Structure determination of gama-Fe4N and epsilon-Fe3N. Jornal of Alloys and Compounds. 1995, vol. 277, pp. 10-17.

[8] PYE, D. Nitriding Techniques and Methods. Steel Heat Treatment Handbook. Marcel Dekker, Inc., 1997, pp. 721764.

[9] LIEDTKE, D. Härterei Technische Mitteilungen, Bremen: IWT Bremen, 1998.

[10] TOTTEN, G., HOWES, M. Distortion of Heat-Treated Components. Steel Heat Treatment Handbook. New York, Marcel Dekker, Inc., 1997, pp. 251-292.

[11] STEINER, T., MITTEMEIJER, E. Alloying Element Nitride Development in Ferritic Fe-Based Materials Upon Nitiriding: A Review. Journal of Materials Engineering and Performance. 2016, vol. 25, pp. 2091-2102.

[12] CHEUNG, C.T., SIMKOVICH, G. Point defect structure of $\mathrm{Y}^{\prime}$-iron nitride at $450-550^{\circ} \mathrm{C}$. Reactivity of Solids. 1988 , vol. 5, no. 2-3, pp. 177-190.

[13] DOBROCKY, D., POKORNY, Z., STUDENY, P., DOSTAL. Change of selected parameters of steel surface after plasma nitriding. Manufacturing Technology. 2019, vol. 19, no. 2, pp. 204-208. 